\title{
Interactions of Peripheral Endothelin-1 and Nerve Growth Factor as Contributors to Persistent Cutaneous Pain
}

\author{
A. KHODOROVA ${ }^{1}$, Y. ZHANG ${ }^{2}$, G. NICOL ${ }^{2}$, G. STRICHARTZ ${ }^{1}$ \\ ${ }^{1}$ Pain Research Center, Department of Anesthesiology, Perioperative and Pain Medicine, Brigham \\ and Women's Hospital, Harvard Medical School, Boston, MA, USA, ${ }^{2}$ Department of \\ Pharmacology and Toxicology, Indiana University School of Medicine, Indianapolis, IN, USA
}

Received November 29, 2017

Accepted February 2, 2018

\begin{abstract}
Summary
Endothelin-1 (ET-1) and Nerve Growth Factor (NGF) are proteins, released from cancer-ridden tissues, which cause spontaneous pain and hypersensitivity to noxious stimuli. Here we examined the electrophysiological and behavioral effects of these two agents for evidence of their interactions. Individual small-medium cultured DRG sensory neurons responded to both ET-1 (50 nM, $\mathrm{n}=6)$ and NGF ( $100 \mathrm{ng} / \mathrm{ml}, \mathrm{n=}$ ), with increased numbers of action potentials and decreased slow $\mathrm{K}^{+}$currents; pre-exposure to ET-1 potentiated NGF's actions, but not vice versa. Behaviorally, single intraplantar (i.pl.) injection of low doses of ET-1 (20 pmol) or NGF (100 ng), did not increase hindpaw tactile or thermal sensitivity, but their simultaneous injections sensitized the paw to both modalities. Daily i.pl. injections of low ET-1 doses in male rats caused tactile sensitization after 21 days, and enabled further tactile and thermal sensitization from low dose NGF, in ipsilateral and contralateral hindpaws. Single injections of $100 \mathrm{ng}$ NGF, without changing the paw's tactile sensitivity by itself, acutely sensitized the ipsilateral paw to subsequent injections of low ET-1. The sensitization from repeated low ET-1 dosing and the cross-sensitization between NGF and ET-1 were both significantly greater in female than in male rats. These findings reveal a synergistic interaction between cutaneously administered low doses of NGF and ET-1, which could contribute to cancer-related pain.
\end{abstract}

\section{Key words}

Nerve growth factor • Endothelin-1 • Hyperalgesia • Cancer pain - Sex-dependent pain

\section{Corresponding author}

G. R. Strichartz, MRB-611/BWH, 75 Francis Street, Boston, MA 02135-6110, USA. Fax: 617 730-2801. E-mail: gstrichartz@partners.org

\section{Introduction}

Pain from metastasized cancer is notoriously difficult to treat (Lam 2016, Bouhassira et al. 2017). In rodent models, bone cancer-induced pain has been shown to involve multiple soluble factors, including endothelin-1 (ET-1; Peters et al. 2004, Pickering et al. 2008) and Nerve Growth Factor (NGF; Sevcik et al. 2005, Lozano-Ondoua et al. 2013). ET-1 and NGF are synthesized and released from such tumors (Pickering et al. 2008, Yan et al. 2015). Here we have examined the possible interactions of these two agents in awake rats where behavioral assays have revealed heightened pain after these separate agents are locally delivered (Davar et al. 1998, Menendez et al. 2003, Lewin et al. 1994, Khodorova et al. 2013, Khodorova et al. 2017).

ET-1 and NGF work through different membrane receptors and result in the activation of different intracellular signaling pathways. ET-1 acts on two different sub-types of $\mathrm{G}$ protein-coupled receptors (GPCRs), the ETA receptor being the more prominent one for pain and hyperalgesia (Baamonde et al. 2004, Fareed et al. 2000) and the ETB receptor being anti-hyperalgesic in naïve animals but pro-algesic in inflammation or post-operative pain (Khodorova et al. 2003, Khodorova et al. 2009a, Kopruszinski et al. 2018, Motta et al. 2009a). NGF acts on high affinity TrkA receptors and low affinity $\mathrm{p} 75^{\mathrm{NTR}}$ neurotrophin receptors (Meakin and Shooter 1992); in naïve rats the former contributes predominantly to thermal hyperalgesia (Khodorova et al. 2017) and the latter to mechanohyperalgesia (Khodorova et al. 2013), although these associations may change under disease conditions 
(see below).

Both agents enhance sensory neuron excitability, increasing the number of action potentials (AP) from a controlled current stimulus, enhancing the amplitude of voltage-gated, TTX-resistant $\mathrm{Na}^{+}$currents (TTX-R; Zhou et al. 2002, Zhang et al. 2002) and reducing the amplitude of delayed rectifier type $\mathrm{K}^{+}$currents $\left(\mathrm{I}_{\mathrm{K}}\right.$; Zhang et al. 2002, Feng and Strichartz 2009), while also elevating the amplitude and suppressing the desensitization of TRPV1 channel/receptors (Xie and Wang 2009, Bonnington and McNaughton 2003). ET-1 enhances excitability primarily through the ETA isoform of ET-1 GPCRs, linked to an $\alpha \mathrm{Gq} / 11$ G protein (Montmayeur et al. 2011) and ultimately activating PKC $\varepsilon$ (Vellani et al. 2001, Plant et al. 2007), whereas NGF enhances excitability through $\mathrm{p} 75^{\mathrm{NTR}}$, with a reliance on the ceramide-activated atypical PKC (aPKC) PKM $\zeta$ pathway (Zhang et al. 2012).

Since both substances are released from injured, inflamed or cancerous tissues, their possible interactions at peripheral tissues might lead to important insights of mechanisms, therefore we investigated their actions when they were injected together or in sequence.

\section{Methods}

\section{Cellular electrophysiology}

Sensory neurons were isolated from acutely dissected rat dorsal root ganglia by methods described previously (Zhang et al. 2012). All procedures were conducted using protocols approved by the Indiana University School of Medicine and in accord with the Guide for Care and Use of Laboratory Animals (Guide 2011). Whole cell patch clamp was used in the "current clamp" mode to measure the numbers of APs in response to a standardized $1 \mathrm{~s}$ ramp of depolarizing current, set in the control condition to produce $\sim 2-4$ APs. Four to six cells were studied in each protocol. Under voltage clamp, the delayed rectifier $\mathrm{K}^{+}$current, $\mathrm{I}_{\mathrm{K}}$, which is an important determinant of the repeat firing of APs, was determined at the end of a $300 \mathrm{~ms}$ depolarization to $+60 \mathrm{mV}$.

Protocols for determining the acute actions of ET-1 and NGF were organized by first keeping the cells in standard Ringer's solution (Zhang and Nicol 2004), then either: 1) exposing them first to ET-1 (50 nM)containing Ringers for $10 \mathrm{~min}$, and then to NGF (100 ng/ml)-containing Ringers, also for $10 \mathrm{~min}$, or 2) exposing the cells to the same concentrations of NGF and then ET-1, for the same times.

\section{Behavioral studies}

Experiments were conducted in adult, agedmatched Sprague-Dawley rats, males (235-330 g; 53-70 days old) or females (200-210 g; 51-70 days old). Rats were housed in groups of 2 per cage under a 12:12 h dark-light cycle and were provided with food and water ad libitum. Animals were experimentally treated and cared for in accordance with the Guide for the Care and Use of Laboratory Animals (Guide 2011) as reviewed and approved by the Harvard Committee on Animals.

Mechano-sensitivity was determined using a $15 \mathrm{~g}$ von Frey hair (VFH) applied perpendicularly to the plantar surface of a hind paw, as described by Khodorova et al. (2013). This stimulus was applied 10 times, separated by a 3-s interval, in each situation, and the number of brisk withdrawal responses (0-10) determined and compared between the baseline, pre-injection testing and that after the intraplantar (i.pl.) injection of ET-1 and NGF. Withdrawal responses were registered initially on the ipsilateral (injected) paw (ILP) in 4 rats, then on the contralateral paw (CLP). The testing observer was not blind to the identity of the injectate.

The thermal sensitivity of the plantar paw to noxious radiant heat was determined by the method of Hargreaves et al. (1988) using Hargreaves/Plantar test apparatus (IITC, Life Science, Inc., Woodland Hills, CA, USA). The animals were habituated and tested on a raised glass platform over 5-7 days before each experiment to achieve consistent paw withdrawal latency (PWL), as free as possible of stress-related effects. A series of 3-4 withdrawal latencies was determined alternately on left and right paws (more than 4 tests were applied in those few cases of high variability in the initial behavioral responses); the first paw tested was assigned randomly to the left or right. A cut-off time of $20 \mathrm{~s}$ was set to avoid test-induced sensitization. Tests of the same paw were separated by 3-4 min intervals. Measurements for each hind paw, performed on the last two days (including the day of the experiment) before any of the injections, were averaged and the mean value taken as the baseline nociceptive latency. Latency measurements were carried out alternately, first on the injected, ipsilateral paw (ILP) and then on the initially non-injected, contralateral paw (CLP).

\section{Drugs}

NGF- $\beta$ /Carrier Free (rat) (Cat. No. 556-NG100/CF, R\&D systems, Inc., MN, USA) was dissolved in phosphate buffered saline (PBS; $\mathrm{pH}$ 7.4) as a stock 
solution (100 ng/ $\mu \mathrm{l})$. ET-1 (Cat. No. ALX-155-001PC01, Enzo, Life Sciences, Inc., East Farmingdale, NY, USA) stock solution $(200 \mu \mathrm{M})$ was prepared in PBS containing $0.1 \%$ BSA.

\section{Injection procedures}

ET-1, NGF or its vehicle, were injected in a $10 \mu$ l volume subcutaneously (s.c.) into the mid-plantar hind paw, $1 \mathrm{~cm}$ distal from the heel, using a 30-G needle attached to a $10 \mu 1$ Hamilton microsyringe (Hamilton Co., Reno, NV, USA). Injections occurred under brief general anesthesia with the inhalation of the rapidly reversible agent sevoflurane (Abbott Labs, N. Chicago, IL, USA).

\section{Protocols}

Four different questions were explored here, using different protocols, with different groups of rats. Protocol 1: Injections of single low doses of ET-1, and NGF, examining changes in tactile sensitivity $(n=8$, male rats). Protocol 2: Daily injections of low doses of ET-1, with tactile sensitivity assessed $24 \mathrm{~h}$ later, just before the next dose ( $n=8$, male rats; $n=7$, female rats). Protocol 3: Daily repeated injections of NGF with tests for effects of low dose NGF conducted at regular intervals $(n=10$, male rats). Protocol 4: Single injections of low dose NGF followed by injections of low dose ET-1 $(n=7)$. For several of these protocols, as noted in Results, tests for thermal hypersensitivity were also tested, in the same groups.

\section{Data analysis}

Electrophysiological data. Results are presented as the means \pm standard error of the mean (SEM). Statistical differences between the controls and those obtained under various treatment conditions were determined by either an ANOVA or repeated measures (RM) ANOVA when appropriate. When a significant difference was obtained by an ANOVA, posthoc analyses were performed using a Holm-Sidak all-pairs test. If the data set failed the normality test, a KruskalWallis one-way ANOVA on ranks was performed, followed by a Tukey or a Dunn all pairwise tests. Results were considered statistically significant when $\mathrm{P}<0.05$ (SigmaStat 3.5 Software).

Behavioral data. Data are presented as means \pm SEM of the mechanically tested Paw Withdrawal Efficiency (PWE). Statistical analysis used nonparametric tests: Friedman test followed by Dunn post hoc test was applied to compare repeated measures of Paw
Withdrawal Efficiency with baseline values. An unpaired, two-tailed Mann-Whitney U-test was used to compare responses to the same force at the same time point, of the ipsilateral (Treatment, injected) vs. the contralateral (Control, un-injected) paws. Wilcoxon matched pairs (two-tailed) test was applied for comparison of responses at individual times with the baseline response. All statistical tests were conducted using GraphPad InStat version 3.0 (GraphPad Software, La Jolla, CA, USA). $\mathrm{P}<0.05$ was considered significant.

\section{Results}

\section{Cellular electrophysiology}

Both NGF $(100 \mathrm{ng} / \mathrm{ml})$ and ET-1 (50 nM) increased the numbers of APs elicited by a standard current ramp, with ET-1 effect being greater, a $2.85 \pm 0.41$-fold increase over baseline $(n=6)$ vs. $1.85 \pm 0.39(\mathrm{n}=4)$ from NGF, both after 10 min exposure $(\mathrm{P}<0.05)$. There was no change in the resting potential or in the maximum rate-of-rise of the depolarizing phase of APs in the train, from either of the agents, indicating that changes in the early $\mathrm{Na}^{+}$currents were not directly contributing to this action (data not shown). When the cells were next exposed to the other algogen, applied directly after the first one, there was no further significant increase in the numbers of APs $(1.45 \pm 0.31$ for ET- 1 after NGF, $n=4 ; 1.12 \pm 0.11$ for NGF after ET-1, $n=6$ ) or the other parameters.

Both NGF and ET-1 also reduce the slow $\mathrm{K}^{+}$ current, $\mathrm{I}_{\mathrm{K}}$, that is a major factor in determining repetitive AP firing, and is, respectively, linked to activation of $\mathrm{p} 75^{\mathrm{NTR}}$ or ETA receptors. Both algogens reduced $\mathrm{I}_{\mathrm{K}}$ in the same neurons. An initial $10 \mathrm{~min}$ exposure to ET-1 reduced $I_{K}$ to $0.74 \pm 0.07$ of the control value (at $+60 \mathrm{mV}$, $200 \mathrm{~ms}$ ), and this action was not affected by pre-exposure to NGF $(0.78 \pm 0.05$ of value after NGF, $\mathrm{n}=4 ; \mathrm{P}>0.05)$. An initial exposure to NGF reduced $I_{K}$ to $0.83 \pm 0.03$ of control, but if NGF was applied after ET-1, then the reduction was to $0.65 \pm 0.08$ of the ET-1-reduced value $(\mathrm{P}<0.05$, all $\mathrm{n}=4)$. Therefore, ET-1 treatment potentiated these $\mathrm{I}_{\mathrm{K}}$-reducing actions of NGF, but not vice versa.

\section{Behavioral}

Mechano-sensitization from ET-1

Intraplantar injection of high doses $(2 \mathrm{nmol})$ of ET-1 is known to cause overt flinching of the hind paw, which is prevented by systemic morphine, an indication of perceived pain (Fareed et al. 2000). Injections of 0.2 nmol does not cause flinching but does sensitize the 
paw to tactile stimulation such that the response to 10 probes with a $15 \mathrm{~g}$ VFH rises from $1.7 \pm 0.4 / 10$ (pre-injection baseline) to $3.5 \pm 0.5 / 10$ at $25 \mathrm{~h}(\mathrm{P}<0.01)$. Tactile sensitivity of the uninjected, contralateral paw (CLIP) is also increased by ipsilateral $0.2 \mathrm{nmol}$ of ET-1 (from 1.0 \pm 0.4 (Baseline) to $2.9 \pm 0.5$ at $25 \mathrm{~h}(\mathrm{P}<0.05)$. By comparison, injection of single, low doses (20 pmol) of ET-1 in male rats, at $1 \%$ of the threshold dose to cause overt pain, has no effect on tactile sensitivity. Single i.pl. injections of 50-100 ng of NGF also have no effect on tactile sensitivity, and 100-fold higher doses, while inducing sensitivity, never cause overt pain behavior (Khodorova et al. 2013, Mills et al. 2013).
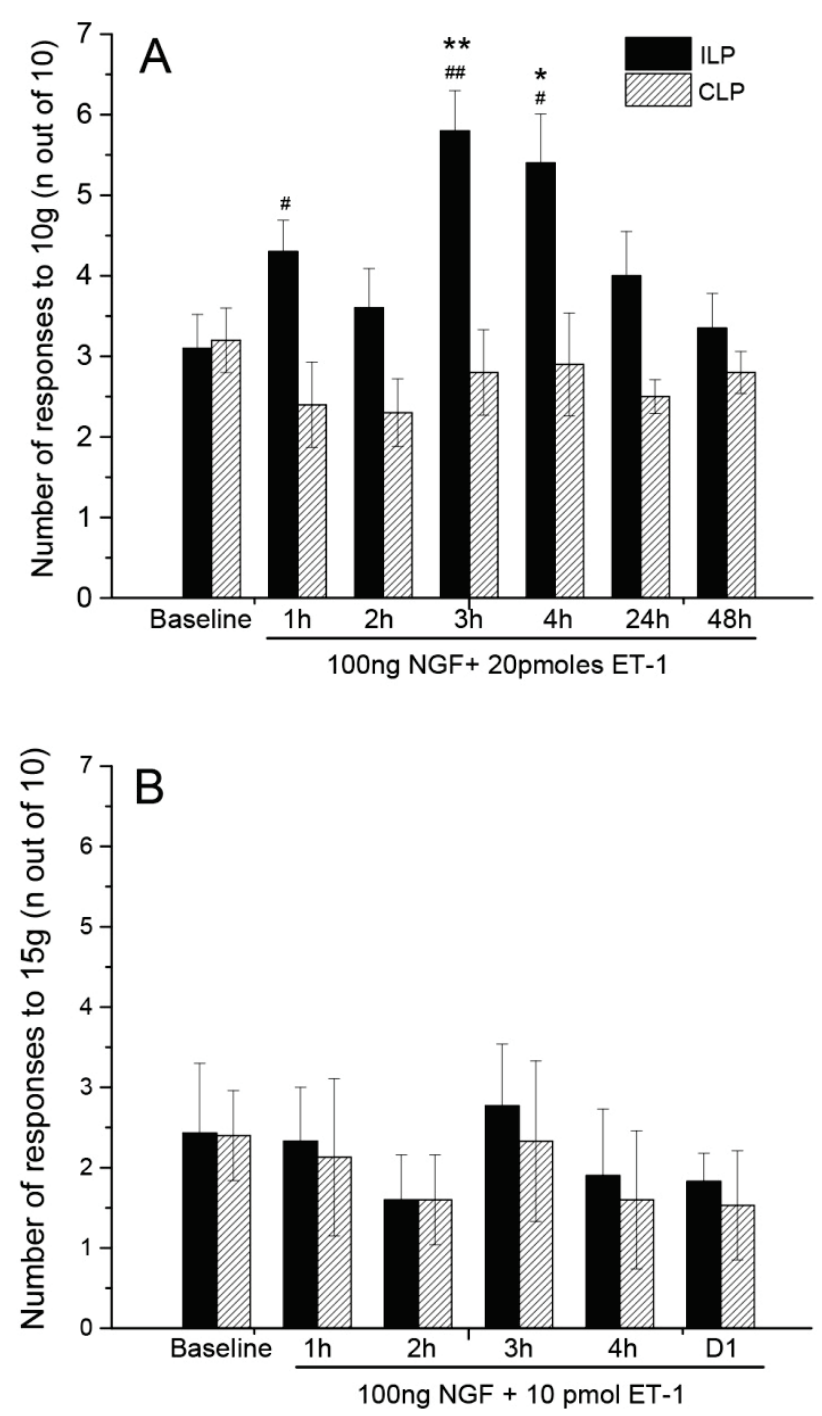

Fig. 1. A. Injection of a mixture of NGF (100 ng) and ET-1 (20 pmol) together causes acute tactile hypersensitivity. B. Co-injections of ET-1 at $10 \mathrm{pmol}$ and $100 \mathrm{ng}$ NGF causes no sensitization. $* \mathrm{P}<0.05, * * \mathrm{P}<0.01$ vs. baseline (Friedman test followed by Dunn test); $\# P<0.05, \# \# P<0.005$ vs. CLP at the respective times (Mann-Whitney test). $n=8$.
However, when these substances are injected together at these low doses, tactile sensitivity was increased in the injected (ipsilateral) paw (ILP), but not in the contralateral paw (CLP) (Fig. 1A). This synergy did not occur with 10 pmol ET-1 (Fig. 1B), implying that $20 \mathrm{pmol}$ is the threshold for such acute potentiation of NGF.

Repetitive, daily injections of 20 pmol ET-1 did elicit a significantly increased tactile responsiveness, but only after 3 weeks (Fig. 2). Repetitive injections of vehicle (phosphate-buffered saline, PBS) into the paw did not change responsiveness (Fig. 2).

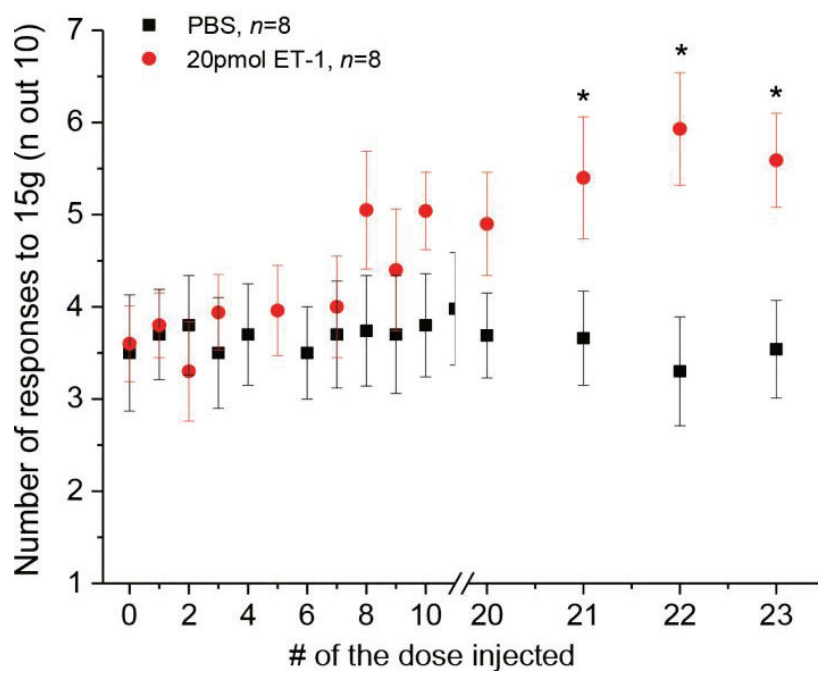

Fig. 2. Changes in tactile responsiveness of the ILP after multiple daily injections of low dose ET-1 (20 pmol). Vehicle (PBS) injections had no such effect. Measurements were performed 22-24 $\mathrm{h}$ after each numbered injection. $* \mathrm{P}<0.05$ vs. PBS-injected values, two-tailed Mann-Whitney test. $n=8$.

\section{Potentiation of the actions of NGF}

Three weeks of daily i.pl. injections of 20 pmol ET-1 sensitized ("primed") the paw to NGF. In naïve male rats, 50 or $100 \mathrm{ng}$ of i.pl. NGF causes no change in mechano-responsiveness (Khodorova et al. 2013), but in ET-1 primed rats, both doses of NGF increased this response (Fig. 3A). Not only does this occur in the ipsilateral paw (ILP), but also in the contralateral paw (CLP), where there is no increased tactile response due to ILP injected ET-1 per se (Fig. 3B). It is noteworthy that the increase in response to NGF injected into the ILP was evident at $3 \mathrm{~h}$, but after NGF injection into the CLP the increased response was not detected at $6 \mathrm{~h}$, but was present at 1 day, suggesting a very slow process underlying this sensitization of the contralateral response. 

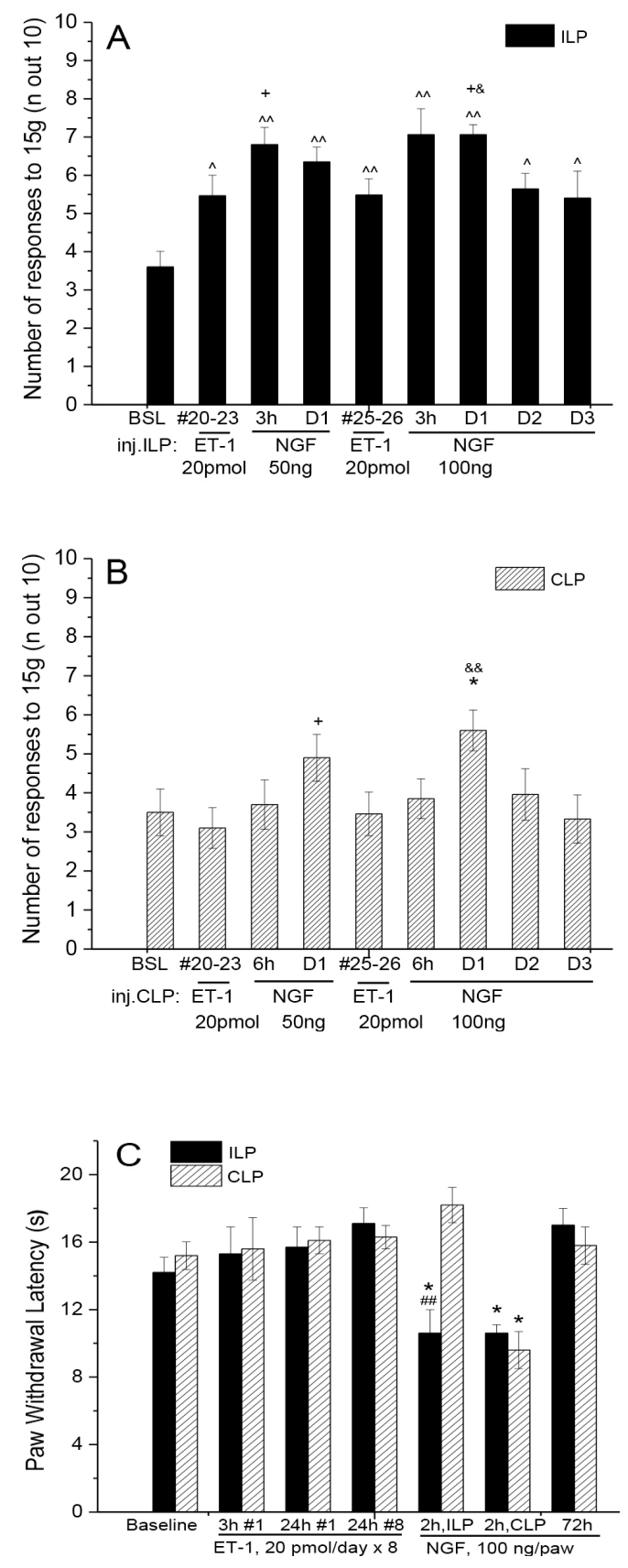

Fig. 3. Low dose NGF after repeated dosing by low dose ET-1. A. After 23-26 daily injections of 20 pmol ET-1 into the left paw (ILP), NGF (50 ng, then $100 \mathrm{ng}$ ) was injected into that same paw and response sensitivity assessed at $3 \mathrm{~h}$ and $24 \mathrm{~h}$ for $50 \mathrm{ng}$, then at 3, 24, 48, $72 \mathrm{~h}$ after $100 \mathrm{ng} \mathrm{NGF;} \wedge \mathrm{P}<0.05, \wedge \wedge \mathrm{P}<0.01 \mathrm{vs}$. BSL (Friedman test $>$ Dunn test); $+\mathrm{P}<0.05$ vs. \#20-23 ET-1 value; $+\& \mathrm{P}<0.05$ vs. \#25-26 ET-1 and D2 values (Wilcoxon test). B. After the same priming by repeated ET-1 as in panel A., NGF at 50 and $100 \mathrm{ng}$ was injected into the contralateral paw, and sensitivity assessed there at 6 and $24 \mathrm{~h}(50 \mathrm{ng})$ and $6,24,48$, $72 \mathrm{~h}$; $* \mathrm{P}<0.05$ vs. BSL and D2 values (Dunn test), $+\mathrm{P}<0.05$ vs. \#20-23 ET-1; \&\&P<0.05 vs. \#25-26 ET-1 and D2 (Wilcoxon test). C. Thermal hyperalgesia caused by sub-threshold NGF after repeated low ET-1. After 8 daily injections of 20 pmol ET-1 into the left paw, $100 \mathrm{ng}$ NGF was injected into that same paw and Paw Withdrawal Latency measured in both paws at $2 \mathrm{~h}$; a second $100 \mathrm{ng}$ NGF injection was made, this time into the right, CLP, and thermal sensitivity was assessed at $2 \mathrm{~h}$ and then at $72 \mathrm{~h}$ after NGF. $* \mathrm{P}<0.05$ vs. Baseline (Friedman test $>$ Dunn test), $\# \# P<0.05$ vs. CLP (Wilcoxon test). $n=10$, for all 3 procedures.

\section{Sensitization to thermal stimulation}

Thermal hyperalgesia, indicated by a shortening of the latency for paw withdrawal from a radiant heat source, is caused by sub-threshold NGF but only after repeated low ET-1. NGF (100 ng) injected into a naïve paw did not affect thermal sensitivity, but after 8 daily injections of 20 pmol ET-1, NGF did cause an acute ipsilateral hyperalgesia (Fig. 3C). A similar thermal sensitization occurred in the CLP, at $2 \mathrm{~h}$ after $100 \mathrm{ng}$ NGF injection there. Low dose NGF caused no such effect after repeated injections of vehicle, and low dose ET-1 alone had no effect on thermal sensitivity (data not shown).

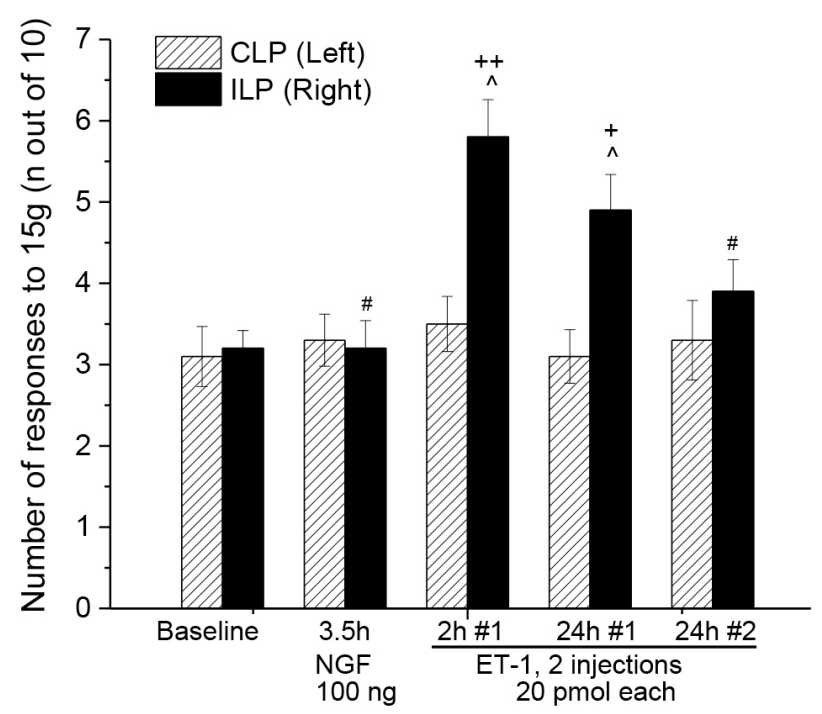

Fig. 4. After one low dose injection of NGF, mechanical hyperalgesia results from one $20 \mathrm{pmol}$ dose of ET-1. NGF alone did not change paw mechanical responsiveness. $n=7 . \wedge p<0.05$ vs. Baseline; \#P<0.05 vs. $2 \mathrm{~h} \# 1 \mathrm{ET}$, Wilcoxon test. $+\mathrm{P}<0.05$, $++\mathrm{P}<0.001$ vs. CLP at the same time point, Mann-Whitney test. $n=7$.

\section{Reciprocal actions of ET-1 and NGF}

ET-1 and NGF cross-sensitize each other. In the ILP, a first injection of $100 \mathrm{ng}$ NGF, which alone has no effect on tactile sensitivity, induces a responsiveness from ET-1 $(20 \mathrm{pmol})$ in the ILP (Fig. 4). In $2 \mathrm{~h}$ the responsiveness is almost doubled by ET-1 injection; $24 \mathrm{~h}$ later the sensitization is smaller but still significant. A second injection of low dose ET-1, given shortly after this assessment, does not sensitize the paw as much as the first injection of ET-1, suggesting that either the priming effect of low NGF has faded or that tachyphylaxis occurs for the sensitizing actions of low ET.

In contrast to the duration of priming from low NGF, if a much higher single dose of NGF (3-4 $\mu \mathrm{g})$ is 
injected, tactile sensitivity does increase, for $\sim 5$ days, and sensitization to low dose ET-1 outlasts this transient tactile hypersensitivity (data not shown). However, neither low nor high dose NGF sensitizes the CLP.

\section{Sex-dependent sensitization}

All preceding results were from male rats. Surprisingly, female rats showed greater changes in responsiveness than males. Repeated, daily i.pl. injections of 20 pmol of ET-1 resulted in an earlier and greater increase of tactile sensitivity (Fig. 5). Responsiveness increased significantly above baseline by 5 daily injections vs. only after 21 daily injections in males, and had a greater maximum change (3.20 \pm 0.42 -fold increase over Baseline; $\mathrm{n}=7)$ than in males (1.60 0.26 -fold increase over Baseline, $\mathrm{n}=8 ; \mathrm{P}<0.01$, Mann-Whitney test). Female rats also showed a greater sensitization to NGF by a series of low dose ET-1 injections, compared to males. After 7 daily injections of 20 pmol ET-1, a single ILP injection of $50 \mathrm{ng}$ NGF into female rat paws resulted in an increase over baseline of 2.9-fold (data not shown), significantly greater than the 1.8 -fold increase over baseline for male rats $(\mathrm{P}>0.05$, Wilcoxon test).

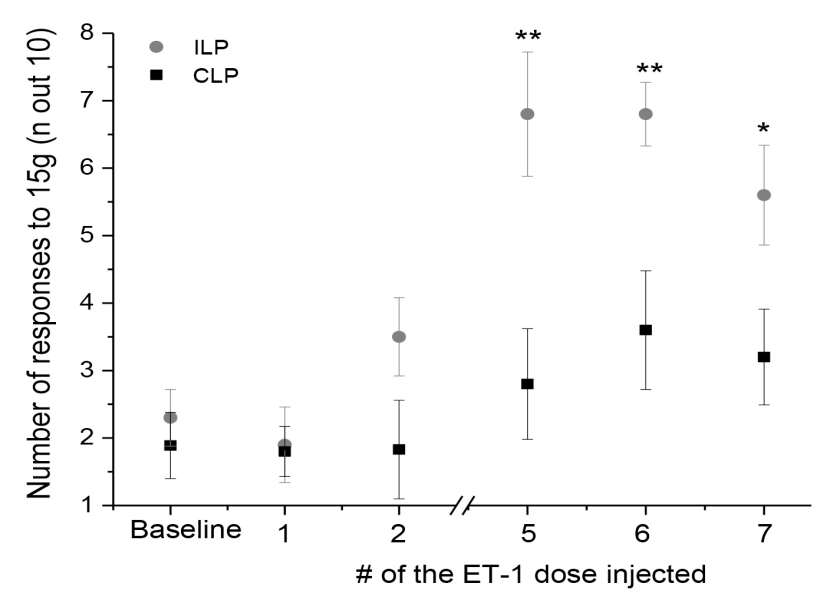

Fig. 5. Enhanced responsiveness of the ILP of female rats to mechanical stimulation from repeated daily injections of $20 \mathrm{pmol}$ of ET-1. The measurements were performed on the day (at 22-24 h) after each injection $(n=7)$. ILP - ipsilateral paw. $* * \mathrm{P}<0.01$ vs. Baseline value, $* \mathrm{P}<0.05$ vs. dose $\# 1$ value, (Friedman test $>$ Dunn test).

In analogous experiments on the CLP, female rats' responsiveness was almost doubled by a single, 50 ng NGF injection into the CLP after 7 low dose ET-1 injections into the ILP. Responsiveness increased to 2.9-fold of baseline in females compared to only 1.4-fold of baseline in males. Overall, female rats' tactile sensitivity was increased more than males, both to repeated low dose ET-1 and to the subsequent injection of low dose NGF, and to the higher dose of NGF, which raised the response efficiency to a peak of $6.35 \pm 0.49$ in males vs. $9.97 \pm 0.03$ in females $(\mathrm{P}<0.0002$, MannWhitney test). These increased elevations in females lasted for at least $48 \mathrm{~h}$, in both paws, compared to the less than $24 \mathrm{~h}$ duration in males.

\section{Discussion}

The results of the cellular electrophysiological experiments show that the soma of, most likely, nociceptive cells, are sensitive to both ET-1 and NGF. Both agents increased the number of APs stimulated by a standard current stimulus, without changing the resting potential or the maximum rate-of-rise of the APs in the train. This last observation suggests that fast voltagegated $\mathrm{Na}^{+}$currents, which are primary drivers of AP depolarization, are not altered by ET-1, although the slower, TTX-R $\mathrm{Na}^{+}$currents in sensory neurons are known to be enhanced by ET-1, via ETA receptors (Zhou et al. 2002), and by NGF, via $\mathrm{p} 75^{\mathrm{NTR}}$ (Zhang and Nicol 2004). It is important to note that Mule et al. (2018) have found the opposite actions of ET-1 on sensory neurons, namely a reduction in excitability and $\mathrm{Na}^{+}$currents, and an increase in $I_{K}$, both dependent on ETB. The slow $I_{K}$ also was affected separately by ET-1 and NGF, as shown previously, and here in the same neurons, with a potentiation of NGF's effect by pre-exposure to ET-1, but no effect of NGF pre-exposure on ET-1 actions. In the setting of a metastasizing tumor, when NGF and ET-1 are both being released, it is likely that the continued presence of ET-1 will potentiate the NGF that is also continuously released, keeping in mind that these are acute responses to brief exposures. Due to the short lifetime of acutely isolated neurons, it is not possible to study the effects of exposures to algogens lasting weeks, as would occur in the cancer setting.

Behaviorally, a single dose of ET-1 injected into the hind paw at $1 \%$ of the minimum dose to produce overt pain behavior has no effect, but repeated delivery of this dose will result in tactile sensitization: after 21 doses for male rats and 5-6 doses for female rats. The doses applied contain concentrations of ET-1 much higher than those detected in experimental tumors (Pickering et al. 2008), or plasma of cancer patients (Yan et al. 2015), although those tissues present a continuous source of endothelin whereas we gave only daily boluses which 
would be rapidly absorbed and diluted by local tissues and vasculature. Using a continuous delivery of ET-1 $(24 \mu \mathrm{g} /$ day $)$ for 7 days from a subcutaneous catheter placed under the dorso-lateral skin of the rat, and connected to an osmotic minipump. Hans et al. (2009) also found an increase in mechano-responsiveness, although they did not examine any interactions with other tumor-released substances.

Single injections of higher doses of ET-1 and NGF alone are known to sensitize the rat paw to mechanical (Balonov et al. 2006, Mills et al. 2013) and thermal (Mills et al. 2013, Khodorova et al. 2017) stimulation. Although single low doses of either algogen are ineffective, together they do increase hindpaw tactile sensitivity. Furthermore, cross-sensitization is revealed when sequential paw injections of ET-1 $\rightarrow$ NGF or of NGF $\rightarrow$ ET-1 are made at these low doses. This crosssensitization could contribute importantly to hyperalgesia from injury and cancer, since both agents are released from injured (Mujenda et al. 2007, Wu et al. 2007) or cancerous (Schmidt et al. 2007, Schmidt 2014) tissues, and contribute to cancer-related pain (Fujita et al. 2008, Ye et al. 2011). In this Discussion we address what mechanisms might account for this reciprocal sensitization.

Several different schemes could account for the super-additive and cross-sensitizing interactions between ET-1 and NGF. First, there are peripheral actions. Both agents act on the same peripheral nociceptor terminals, increasing electrical excitability, acutely enhancing the TTX-R Na ${ }^{+}$currents (Zhou et al. 2002, Zhang et al. 2002), reducing the delayed rectifier $K^{+}$currents, $I_{K}$ (Feng and Strichartz 2009, Zhang et al. 20002), and amplifying TRPV1 currents while suppressing its desensitization (Shu and Mendell 1999, Shu and Mendell 2001, Plant et al. 2007, Kawamata et al. 2008). When repeatedly delivered or persistently present these actions will lead to prolonged depolarizations and to repetitive, spontaneous APs; the former will stimulate the entry of $\mathrm{Ca}^{+2}$ (Zhou et al. 2001) and the release of pro-inflammatory agents, such as ATP (Donnelly-Roberts et al. 2008), that will further activate the substancereleasing neurite endings (autocrine action) and also act on other local cells, including other neurites and keratinocytes. These local cells contain and release pro-nociceptive substances, such as CGRP and ET-1 itself (Hou et al. 2011, Khodorova et al. 2009b), facilitating a persistent, positive feedback cycle for nociceptor excitation. Reciprocally, P2X4 receptors for
ATP, located on neurons, are potentiated by acute exposure to ET-1 (Barr et al. 2014), supporting a positive feedback loop between keratinocytes and epidermal neurites that might last beyond the initial stimulation.

Furthermore, NGF, acting through TrkA receptors, forms a complex that migrates to the soma in the DRG and stimulates the synthesis of new pro-excitatory proteins, which will act to switch the pain-sensing system into a permanent hyperexcitable condition (Yamashita et al. 2017). Interestingly, protein synthesis may also be involved in the acute as well as a long-term sensitization by ET-1. It has been recently shown that the increased excitability from NGF exposure of isolated sensory neurons depends on protein transcription, and that the essential product is an atypical PKC, PKM $\zeta$ (Kays et al. 2017). The same paper reported that behavioral hypersensitivity from paw-injected NGF was delayed, or reversed, by transcriptional inhibitors acting in the paw, and that an atypical PKC antagonist had an identical action, implying that PKM $\zeta$ synthesis in distal neurites, far from the sensory cell body, is critical for such sensitization. This antagonist also suppressed, but did not eliminate, ET-1-induced paw sensitization, suggesting a contribution of an aPKC to ET-1 distal actions. Broadly speaking, an alteration of the local cellular environment could account for prolonged tactile sensitization through peripheral, interactive mechanisms.

Second, a centrally localized interaction could occur, for example in the dorsal horn, from the tonic discharge of peripheral nociceptors (Baron et al. 2013), with substances released by and cross-reacting with either pre-synaptic or post-synaptic neurons, or non-neuronal, e.g. glial cells (Ji et al. 2014). The central projections and transmitting substances for NGF-activated nociceptors must differ somewhat from those of ET-1 activated nociceptors, since the latter can effect an acute nocifensive, e.g. flinching response, the former not, and also since single intraplantar injections of ET-1 cause contralateral sensitization, yet NGF does not.

ET-1 at high doses $(2-8 \mathrm{nmol})$ induces spike responses in C- and A delta-nociceptors and a spontaneous nocifensive (morphine-sensitive), dosedependent flinching response of the injected hindpaw (Davar et al. 1998, Gokin et al. 2001). This acute nocifensive response is followed by an acute (at $2 \mathrm{~h}$ ) ipsilateral and a delayed contralateral sensitization to mechanical stimulation that is present in both paws for at least $48 \mathrm{~h}$ (Khodorova and Strichartz 2010, Strichartz et al. 2015). Local anesthetic block of the ipsilateral sciatic 
nerve during the period of initial response to ipsilateral ET-1 prevents contralateral sensitization (Khodorova and Strichartz 2010) indicating the importance of local afferent impulse transmission and central (spinal) processing (Houck et al. 2004), and block of conduction in the contralateral sciatic nerve, and paw, also prevents contralateral sensitization, implicating efferent conduction in the overall process (Strichartz et al. 2015). In the present paper we observed that NGF injected into the CLP after repetitive ET-1 injections caused a contralateral sensitization that required longer than $6 \mathrm{~h}$ to appear (Fig. 3B). This is much longer than the post-translational modification, e.g. phosphorylation, of existing proteins and suggests that protein synthesis in the CLP is triggered by ET-1 actions on the ILP.

In summary, very low doses of ET-1 and NGF, both of which are known to be involved in the pain caused by certain metastasizing tumors, cause pain hypersensitivity after repeated injections into the paw, or when combined in a single dose. Both agents act acutely on ion channels that control hyperexcitability in nociceptive neurons, although the details of their individual behavioral actions in vivo differ, suggesting that their central (spinal) connections are different. Prolonged changes in central connectivity could result from the prolonged release of neurotransmitters and neuropeptides in the dorsal horn, but there also is accumulating evidence for long-term changes in distal, cutaneous nociceptor endings, due to protein synthesis at these loci.

\section{Conflict of Interest}

There is no conflict of interest.

\section{Acknowledgements}

Supported by CA080153 (to GS) and NS078173 (to GN).

\begin{abstract}
Abbreviations
$\mathrm{AP}$, action potential; aPKC, atypical protein kinase $\mathrm{C}$; CLP, contralateral paw; ET-1, endothelin-1; ETA, endothelin receptor $\mathrm{A}$; $\mathrm{ETB}$, endothelin receptor $\mathrm{B}$; GPCR, G protein-coupled receptor; i.pl., intraplantar; $\mathrm{I}_{\mathrm{K}}$, delayed rectifier type potassium channels; ILP, ipsilateral paw; NGF, nerve growth factor; $\mathrm{P}_{2} \mathrm{X}_{4}$, purinergic type $2 \mathrm{X} 4$ receptor; $\mathrm{p} 75^{\mathrm{NTR}}$, p75 neurotrophin receptor; PBS, phosphate buffered saline; $\mathrm{PKM} \zeta$, protein kinase $\mathrm{M}$ zeta; TRK A, tyrosine kinase receptor A; TRPV-1, transient receptor potential vanilloid type-1 receptor; TTX-R, tetrodotoxin resistant sodium channels; VFH, von Frey filament.
\end{abstract}

\section{References}

BAAMONDE A, LASTRA A, VILLAZON M, BORDALLO J, HILDAGO A, MENENDEZ L: Involvement of endogenous endothelins in thermal and mechanical inflammatory hyperalgesia in mice. Naunyn Schmiedebergs Arch Pharmacol 369: 245-251, 2004.

BALONOV K, KHODOROVA A, STRICHARTZ GR: Tactile allodynia initiated by local subcutaneous endothelin-1 is prolonged by activation of TRPV-1 receptors. Exp Biol Med 231: 1165-1170, 2006.

BARON R, HANS G, DICKENSON AH: Peripheral input and its importance for central sensitization. Ann Neurol 74: 630-636, 2013.

BARR T, HRNJIC A, KHODOROVA A, SPRAGUE J, STRICHARTZ G: Sensitization of cutaneous neuronal purinergic receptors contributes to endothelin-1-induced mechanical hypersensitivity. Pain 155: 1091-1101, 2014.

BONNINGTON JK, MCNAUGHTON PA: Signalling pathways involved in the sensitization of mouse nociceptive neurones by nerve growth factor. J Physiol 551: 433-446, 2003.

BOUHASSIRA D, LUPORSI E, KRAKOWSKI I: Prevalence and incidence of chronic pain with or without neuropathic characteristics in patients with cancer. Pain 158: 1118-1125, 2017.

DAVAR G, HANS G, FAREED MU, SINNOTT C, STRICHARTZ G: Behavioral signs of acute pain produced by application of endothelin-1 to rat sciatic nerve. Neuroreport 9: 2279-2283, 1998.

DONNELLY-ROBERTS D, MCGARAUGHTY S, SHIEH CC, HONORE P, JARVIS MF: Painful purinergic receptors. J Pharmacol Exp Ther 324: 409-415, 2008.

FAREED MU, HANS GH, ATANDA A JR, STRICHARTZ GR, DAVAR G: Pharmacologic characterization of acute pain behavior produced by application of endothelin-1 to rat sciatic nerve. J Pain 1: 46-53, 2000. 
FENG B, STRICHARTZ G: Endothelin-1 raises excitability and reduces potassium currents in sensory neurons. Brain Res Bull 79: 345-350, 2009.

FUJITA M, ANDOH T, SAIKI I, KURAISHI Y: Involvement of endothelin and ET(A) endothelin receptor in mechanical allodynia in mice given orthotopic melanoma inoculation. J Pharmacol Sci 106: 257-263, 2008.

GOKIN AP, FAREED MU, PAN H-L, HANS G, STRICHARTZ GR, DAVAR G: Local injection of endothelin-1 produces pain-like behavior and excitation of nociceptors in rats. J Neurosci 21: 5358-5366, 2001.

GUIDE FOR THE CARE AND USE OF LABORATORY ANIMALS. National Academies Press, Washington D.C., 2011.

HANS G, DESEURE K, VERCAUTEREN M: Altered sensitivity to mechanical stimulation during prolonged subcutaneous administration of endothelin-1 in rats. J Pain Res 2: 67-73, 2009.

HARGREAVES K, DUBNER R, BROWN F, FLORES C, JORIS J: A new and sensitive method for measuring thermal nociception in cutaneous hyperalgesia. Pain 32: 77-88, 1988.

HOU Q, BARR T, GEE L, VICKERS J, WYMER J, BORSANI E, RODELLA L, GETSIOS S, BURDO T, EISENBERG E, GUHA U, LAVKER R, KESSLER J, CHITTUR S, FIORINO D, RICE F, ALBRECHT P: Keratinocyte expression of calcitonin gene-related peptide $\beta$ : implications for neuropathic and inflammatory pain mechanisms. Pain 152: 2036-2051, 2011.

HOUCK CS, KHODOROVA A, REALE A, STRICHARTZ GR, DAVAR G: Sensory fibers resistant to the actions of tetrodotoxin mediate nocifensive responses to local administration of endothelin-1 in rats. Pain 110: 719-726, 2004.

JI RR, XU ZZ, GAO YJ: Emerging targets in neuroinflammation-driven chronic pain. Nat Rev Drug Discov 13: 533-548, 2014.

KAWAMATA T, JI W, YAMAMOTO J, NIIYAMA Y, FURUSE S, NAMIKI A: Contribution of transient receptor potential vanilloid subfamily 1 to endothelin-1-induced thermal hyperalgesia. Neuroscience 154: 1067-1076, 2008.

KAYS J, ZHANG YH, KHORODOVA A, STRICHARTZ G, NICOL GD: Peripheral synthesis of an atypical protein kinase $\mathrm{C}$ mediates the enhancement of excitability and the development of mechanical hyperalgesia produced by nerve growth factor. Neuroscience 371: 420-432, 2017.

KHODOROVA A, STRICHARTZ G: Contralateral paw sensitization following injection of endothelin-1: effects of local anesthetics differentiate peripheral and central processes. Neuroscience 165: 553-560, 2010.

KHODOROVA A, NAVARRO B, JOUAVILLE S, MURPHY J-E, RICE F, MATZURKIEWICZ JE, LONGWOODWARD D, STOFFEL M, STRICHARTZ GR, YUKHANANOV R, DAVAR G: Endothelin-B receptor activation triggers an endogenous analgesic cascade at sites of peripheral injury. Nature Med 9: 1055-1061, 2003.

KHODOROVA A, ZOU S, REN K, DUBNER R, DAVAR G, STRICHARTZ G: Dual roles for endothelin-B receptors in modulating adjuvant-induced inflammatory hyperalgesia in rats. Open Pain $J$ 2: 30-40, 2009a.

KHODOROVA A, RICHTER J, VASKO MR, STRICHARTZ G: Early and late contributions of glutamate and CGRP to mechanical sensitization by endothelin-1. J Pain 10: 740-749, 2009b.

KHODOROVA A, NICOL G, STRICHARTZ G: The p75NTR signaling cascade mediates mechanical hyperalgesia induced by nerve growth factor injected into the rat hind paw. Neuroscience 254: 312-323, 2013.

KHODOROVA A, NICOL GD, STRICHARTZ G: The Trk-A receptor mediates experimental thermal hyperalgesia produced by nerve growth factor: modulation by the p75 neurotrophin receptor. Neuroscience 340: 384-397, 2017.

KOPRUSZINSKI CM, DOs REIS RC, GAMBETA E, ACCO A, RAE GA, KING T, CHICHORRO JG: Blockade of endothelin receptors reduces tumor-induced ongoing pain and evoked hypersensitivity in a rat model of facial carcinoma induced pain. Eur J Pharmacol 818: 132-140, 2018.

LAM DK: Emerging factors in the progression of cancer-related pain. Pain Manag 6: 487-496, 2016.

LEWIN GR, RUEFF A, MENDELL LM: Peripheral and central mechanisms of NGF-induced hyperalgesia. Eur $J$ Neurosci 6: 1903-1912, 1994.

LOZANO-ONDOUA AN1, SYMONS-LIGUORI AM, VANDERAH TW: Cancer-induced bone pain: mechanisms and models. Neurosci Lett 557: 52-59, 2013. 
MEAKIN SO, SHOOTER EM: The nerve growth factor family of receptors. Trends Neurosci 15: 323-333, 1992.

MENÉNDEZ L, LASTRA A, HIDALGO A, BAAMONDE A: Nociceptive reaction and thermal hyperalgesia induced by local ET-1 in mice: a behavioral and Fos study. Naunyn Schmiedebergs Arch Pharmacol 367: 28-34, 2003.

MILLS CD, NGUYEN T, TANGA FY, ZHONG C, GAUVIN DM, MIKUSA J, GOMEZ EJ, SALYERS AK, BANNON AW: Characterization of nerve growth factor-induced mechanical and thermal hypersensitivity in rats. Eur J Pain 17: 469-479, 2013.

MONTMAYEUR JP, BARR TP, KAM SA, PACKER SJ, STRICHARTZ GR: ET-1 induced elevation of intracellular calcium in clonal neuronal and embryonic kidney cells involves endogenous endothelin-A receptors linked to phospholipase C through Gaq/11. Pharmacol Res 64: 258-267, 2011.

MOTTA EM, CALIXTO JB, RAE GA: Mechanical hyperalgesia induced by endothelin-1 in rats is mediated via phospholipase C, protein kinase C, and MAP kinases. Exp Biol Med (Maywood) 231: 1141-1145, 2006.

MOTTA EM, CHICHORRO JG, D'ORLÉANS-JUSTE P, RAE GA: Roles of endothelin ETA and ETB receptors in nociception and chemical, thermal and mechanical hyperalgesia induced by endothelin-1 in the rat hindpaw. Peptides 30: 918-925, 2009a.

MOTTA EM, CHICHORRO JG, RAE GA: Role of ET(A) and ET(B) endothelin receptors on endothelin-1-induced potentiation of nociceptive and thermal hyperalgesic responses evoked by capsaicin in rats. Neurosci Lett 457: 146-150, 2009b.

MUJENDA FH, DUARTE AM, REILLY EK, STRICHARTZ GR: Cutaneous endothelin-A receptors elevate postincisional pain. Pain 133: 161-173, 2007.

MULE NK, SINGH JN, SHAH KU, GULATI A, SHARMA SS: Endothelin-1 decreases excitability of the dorsal root ganglion neurons via $\mathrm{ET}_{\mathrm{B}}$ receptor. Mol Neurobiol 55: 4297-4310, 2018.

PETERS CM, LINDSAY TH, POMONIS JD, LUGER NM, GHILARDI JR, SEVCIK MA, MANTYH PW: Endothelin and the tumorigenic component of bone cancer pain. Neuroscience 126: 1043-1052, 2004.

PICKERING V, JAY GUPTA R, QUANG P, JORDAN RC, SCHMIDT BL: Effect of peripheral endothelin-1 concentration on carcinoma-induced pain in mice. Eur J Pain 12: 293-300, 2008.

PLANT TD, ZÖLLNER C, KEPURA F, MOUSA SS, EICHHORST J, SCHAEFER M, FURKERT J, STEIN C, OKSCHE A: Endothelin potentiates TRPV1 via ETA receptor-mediated activation of protein kinase C. Mol Pain 3: 35, 2007.

SCHMIDT BL: The neurobiology of cancer pain. Neuroscientist 20: 546-562, 2014.

SCHMIDT BL, PICKERING V, LIU S, QUANG P, DOLAN J, CONNELLY ST, JORDAN RC: Peripheral endothelin A receptor antagonism attenuates carcinoma-induced pain. Eur J Pain 11: 406-414, 2007.

SEVCIK MA, GHILARDI JR, PETERS CM, LINDSAY TH, HALVORSON KG, JONAS BM, KUBOTA K, KUSKOWSKI MA, BOUSTANY L, SHELTON DL, MANTYH PW: Anti-NGF therapy profoundly reduces bone cancer pain and the accompanying increase in markers of peripheral and central sensitization. Pain 115: 128-141, 2005.

SHU X-Q, MENDELL LM: Nerve growth factor acutely sensitizes the response of adult rat sensory neurons to capsaicin. Neurosci Lett 274: 159-162, 1999.

SHU X-Q, MENDELL LM: Acute sensitization by NGF of the response of small-diameter sensory neurons to capsaicin. J Neurophysiol 86: 2931-2938, 2001.

STRICHARTZ GR, KHODOROVA A, WANG JC, CHEN YW, HUANG CC: Contralateral hyperalgesia from injection of ET-1 into the ipsilateral paw requires efferent conduction into the contralateral paw. Anesth Analg 121: 1065-1077, 2015.

VELLANI V, MAPPLEBECK S, MORIONDO A, DAVIS JB, MCNAUGHTON PA: Protein kinase C activation potentiates gating of the vanilloid receptor VR1 by capsaicin, protons, heat and anandamide. $J$ Physiol 534: 813-825, 2001.

XIE C, WANG DH: Ablation of transient receptor potential vanilloid 1 abolishes endothelin-induced increases in afferent renal nerve activity: mechanisms and functional significance. Hypertension 54: 1298-1305, 2009.

YAMASHITA N, JOSHI R, ZHANG S, ZHANG ZY, KURUVILLA R: Phospho-regulation of soma-to-axon transcytosis of neurotrophin receptors. Dev Cell 42: 626-639, 2017. 
YAN XB, PENG TC, HUANG D: Correlations between plasma endothelin-1 levels and breakthrough pain in patients with cancer. Onco Targets Ther 8: 3703-3706, 2015.

YE Y, DANG D, ZHANG J, VIET CT, LAM DK, DOLAN JC, GIBBS JL, SCHMIDT BL: Nerve growth factor links oral cancer progression, pain and cachexia. Mol Cancer Ther 10: 1667-1676, 2011.

ZHANG YH, NICOL GD: NGF-mediated sensitization of the excitability of rat sensory neurons is prevented by a blocking antibody to the p75 neurotrophin receptor. Neurosci Lett 366: 187-192, 2004.

ZHANG YH, VASKO MR, NICOL GD: Ceramide, a putative second messenger for nerve growth factor, modulates the TTX-resistant $\mathrm{Na}(+)$ current and delayed rectifier $\mathrm{K}(+)$ current in rat sensory neurons. $J$ Physiol 544: 385-402, 2002.

ZHANG YH, KAYS J, HODGDON KE, SACKTOR TC, NICOL GD: Nerve growth factor enhances the excitability of rat sensory neurons through activation of the atypical protein kinase $\mathrm{C}$ isoform, PKM $\zeta . J$ Neurophysiol 107: 315-335, 2012.

ZHOU QL, STRICHARTZ G, DAVAR G: Endothelin-1 activates ETA receptors to increase intracellular calcium in model sensory neurons. Neuroreport 12: 3853-3857, 2001.

ZHOU Z, DAVAR G, STRICHARTZ G: Endothelin-1 (ET-1) selectively enhances the activation gating of slowly inactivating tetrodotoxin-resistant sodium currents in rat sensory neurons: a mechanism for the pain-inducing actions of ET-1. J Neurosci 22: 6325-6330, 2002. 